\title{
Rate and Predictors of Neonatal Jaundice in Northwest Ethiopia: Prospective Cohort Study
}

This article was published in the following Dove Press journal:

Journal of Multidisciplinary Healthcare

\author{
Molla Yigzaw Birhanu' \\ Aytenew Atnaf Workineh ${ }^{2}$ \\ Yalew Molla ${ }^{3}$ \\ Ermias Abebaw ${ }^{4}$ \\ Amit Arora ${ }^{5}$ \\ Yibelu Bazezew 6 \\ 'Department of Public Health, College of \\ Health Sciences, Debre Markos \\ University, Debre Markos, Ethiopia; \\ ${ }^{2}$ Department of Medical Laboratory \\ Sciences, College of Health Sciences, \\ Debre Markos University, Debre Markos, \\ Ethiopia; ${ }^{3}$ Department of Pharmacy, \\ College of Health Sciences, Debre \\ Markos University, Debre Markos, \\ Ethiopia; ${ }^{4}$ Department of Pediatrics, \\ School of Medicine, Debre Markos \\ University, Debre Markos, Ethiopia; \\ ${ }^{5}$ School of Health Sciences, Western \\ Sydney University, Penrith, NSW, 275I, \\ Australia; ${ }^{6}$ Department of Midwifery, \\ College of Health Sciences, Debre \\ Markos University, Debre Markos, \\ Ethiopia
}

Background: Neonatal jaundice is one of the most common clinical disorders occurred worldwide. About 1.1 million neonates develop jaundice per year globally and the vast majority of them found in sub-Saharan Africa and South Asia. There is a paucity of evidence on the incidence rate and predictors of neonatal jaundice in Ethiopia. Therefore, this study was aimed at determining the rate and predictors of neonatal jaundice in the northwest, Ethiopia.

Methods: A prospective cohort study design was conducted at Debre Markos comprehensive, specialized Hospitals using 334 neonates from October 1, 2019, to June 30, 2020. Using a systematic random sampling technique, the study subjects were drawn. Data were entered into the Epi-Data ${ }^{\mathrm{TM}}$ Version 4.2 and analyzed using STATA ${ }^{\mathrm{TM}}$ Version 14.0. The KaplanMeier survival curve was used to estimate the survival time. A generalized Log rank test was used to compare the survival curves of different categorical variables. Finally, both bivariable and multivariable Cox-proportional hazards regression models were used to identify the predictors of neonatal jaundice.

The Results: The overall incidence rate of jaundice among neonates was 4.5 per 100 person-hours. Long duration of labor $[\mathrm{ARR}=3.5 ; 95 \%$ confidence interval (CI), (2.88.7)], being male neonates $[\mathrm{ARR}=5.2 ; 95 \% \mathrm{CI}(3.5-7.3)]$, "O" blood group mothers $[\mathrm{ARR}=4.5 ; 95 \% \mathrm{CI}(3.4-10.3)]$, and having neonatal sepsis $3.4[\mathrm{ARR}=3.4 ; 95 \% \mathrm{CI}$ : (2.5-6.1)] were predictors.

Conclusion: The incidence rate of jaundice was higher in this study than the finding of the previous one. Being male, prolonged duration of labor, "O" blood group mothers and sepsis were the significant predictors. Hence, an effort has to be made to decrease the incidence rate of neonatal jaundice through improving newborn care and timely intervention for neonates with sepsis and delivered at a long duration of time as well as the neonates born from "o" blood type mothers are our recommendation.

Keywords: neonatal jaundice, incidence, predictor, NICU, Debre Markos, Ethiopia

\section{Background}

Jaundice is one of the most common medical complications causing neonatal readmission during the neonatal period. ${ }^{1,2}$ It is a preventable and treatable clinical complication, but letting untreated can end up in neonatal mortality. The occurrence of jaundice among neonates during the first week of their life is $60 \%{ }^{3,4}$ among term and $80 \%{ }^{4,5}$ among preterm newborns. Neonatal jaundice is the most common cause of readmission for neonates during their neonatal period. ${ }^{6}$ It is accountable for $70 \%$ and $10 \%$ of neonatal morbidity and mortality, respectively, worldwide. ${ }^{5,7}$ As an earlier report indicated that, out of the 130 million babies born per year, approximately 4 million died within their neonatal period. ${ }^{8}$ Of the total neonatal mortality
Correspondence: Molla Yigzaw Birhanu Health Sciences, Debre Markos University, P.O. Box 269, Debre Markos, Ethiopia

Tel +251910614947

Email mollayigzaw33@gmail.com
Journal of Multidisciplinary Healthcare 2021:14 447-457

447

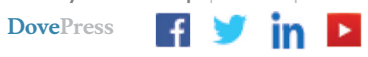

f 
secondary to jaundice complications, about $75 \%$ of neonatal mortality occurred in South Asia and sub-Saharan Africa. ${ }^{9}$ In Ethiopia, neonatal mortality and morbidity are among the highest in the world, on which ${ }^{6}$ more than onethird of childhood death occurs within the first 28 days of age. ${ }^{10}$ The incidence of neonatal jaundice in Nepal was 29.3 per 1000 live births, ${ }^{11}$ in Turkish 31\%. ${ }^{12}$

When we come with the burden of jaundice, about 7\% to $13 \%$ of all neonatal deaths in Bangladesh were accounted for by jaundice. ${ }^{13}$ Of the total neonatal mortality in Bangladesh, $78 \%$ was occurring during the first week of their life. ${ }^{13}$ Jaundice was one of the most common causes of neonatal mortality and responsive for $6.7 \%$ of neonatal death in Ghana. ${ }^{14}$ In Ethiopia, of the total death at Ayder, about $98.3 \%$ occurred during the first week of their life ${ }^{15}$ and at Aroresa in Sidama, neonatal mortality was 41 per 1000 live birth and neonatal complication was one of the predictors for neonatal mortality. ${ }^{16}$ In the northwest part of Ethiopia, the study revealed that Jaundice was one of the significant predictors for neonatal mortality, especially under 7 days of age. ${ }^{17}$

The predictors of neonatal jaundice were classified as neonatal, obstetric, maternal, and medical factors. Among neonatal and obstetric factors: gestational age,${ }^{18}$ male sex, birth weight, prolonged labor, and primiparity, ${ }^{19}$ normal and oxytocin assisted delivery, ${ }^{20}$ low Appearance Pulse Grimace response Activity Respiration (APGAR) score, and birth asphyxia, ${ }^{21}$ duration of labor, ${ }^{22}$ multiple pregnancies, ${ }^{23}$ and vacuum extraction ${ }^{24}$ were significantly associated with neonatal jaundice. Maternal and medical predictors that had a significant association with neonatal jaundice were as follows: drug use during pregnancy, ${ }^{25}$ maternal age, body mass index, and hemoglobin level, ${ }^{26}$ thyroid-stimulating hormone. ${ }^{27}$ In addition to the above $\mathrm{ABO}$ and $\mathrm{Rh}$ incompatibility, sepsis, and total serum bilirubin level, ${ }^{28}$ maternal smoking status, ${ }^{29}$ cord blood albumin and bilirubin, ${ }^{30}$ low maternal educational status, ${ }^{31}$ parity, ${ }^{32}$ and maternal $\mathrm{O}$ blood group ${ }^{33}$ were the significant predictors of neonatal jaundice.

To tackle this medical complication, the Ethiopian government implemented phototherapy supportive treatment nationally, but nothing has been implemented to prevent the occurrence of the problem locally and globally. Currently, the Ethiopian government targeted to decrease the neonatal mortality rate from $28 / 1000$ live births to $11 /$ 1000 live births by $2035 .^{34}$ To succeed in this plan, data related to the incidence rate and predictors of neonatal jaundice are crucial. There is no record of the rate and predictors of neonatal jaundice in Ethiopia. Thus, we conducted this study to estimate the rate and predictors of jaundice among neonates admitted at Debre Markos Comprehensive specialized Hospital. The results of this study will inform policymakers, program planners working at various levels of maternal, and child health control programs.

\section{Methods}

\section{Study Design, Setting, and Period}

A hospital-based prospective cohort study was undertaken at Debre-Markos comprehensive, specialized Hospital from October 1-2019 to June 30-2020. Debre Markos Town is located at $299 \mathrm{~km}$ far from Addis Ababa, the capital city of Ethiopia, and $265 \mathrm{~km}$ far from Bahir-Dar, the capital city of Amhara Regional State. Debre Markos comprehensive, specialized Hospital provides services for more than 3.6 million people of the East Gojjam Administrative Zone and neighboring areas.

\section{Population}

All neonates admitted to the neonatal intensive care unit of Debre Markos comprehensive, specialized Hospital were the source population. All neonates admitted to the intensive care unit of Debre Markos comprehensive specialized Hospital from October 1-2019 to June 30-2020 were the study population.

\section{Inclusion Criteria}

All neonates admitted to the neonatal intensive care unit of Debre Markos comprehensive, specialized Hospital during the study period were included.

\section{Exclusion Criteria}

Neonates whose mothers were critically ill or unable to give informed consent and Neonates who developed jaundice when they were admitted to NICU of Debre Markos comprehensive specialized Hospital.

\section{Sample Size Determination and Sampling Procedures}

The minimum required sample size was calculated using a single population proportion. We used a STATATM Version 14.0 statistical software to calculate the sample size by considering the following assumptions: level of significance $(\alpha)=5 \%, \mathrm{Za} / 2$ (value at $95 \%$ confidence interval $=1.96$ ), power of $80 \%$, and the prevalence $(\mathrm{P}=0.5$ since there was no 
previous study). We could not apply sample size calculation for predictors since there was no previous study. Hence, the sample size was calculated using a single population proportion for this study. The calculated sample size was found to be 384 , but since the estimated total populations in the study area during the study period were less than 10, 000 the following correction formula was used.

$n f=n i / 1+n i / N=384 / 1+384 / 1500=307$

where

$\mathrm{nf}=$ final sample size

$\mathrm{ni}=$ initial sample size $=384$

$\mathrm{N}=$ total estimated neonates with their mother in the study area during data collection time $=1500$.

Then, after adding 10\% non-response rate to get 338 samples $(307+(307 / 10)=338)$.

In Debre, Markos comprehensive, specialized Hospital, there were 1500 estimated number of neonates admitted to NICU during the study period. We determined the sampling interval $(\mathrm{k})$ by dividing 1500 neonates as the study population $(\mathrm{N})$ by sample size $(\mathrm{n})$ as $(\mathrm{k}=\mathrm{N} / \mathrm{n}=1500 /$ $338=4)$. Then, we systematically selected 338 neonates starting from the second $(2,6,10,14,18$, etc.) neonates and then every fourth neonates who were admitted at the NICU of Debre Markos comprehensive, specialized hospital every day during the study period.

\section{Operational Definition}

Neonate: An infant from birth to 28 days of age.

Jaundice: Refers to the yellow discoloration of the skin and conjunctiva caused by deposition of bilirubin secondary to the bilirubin level in the blood and diagnosed by a physician. ${ }^{2,35}$

Physiological Jaundice: Total bilirubin value along with integrated management of newborn and childhood illness (IMNCI) clinical features of physiological jaundice was used to diagnose physiological jaundice. Neonates in the presence of one more of the established IMNCI criteria (only the skin on the face or eyes yellow and infant aged 2 13 days old) along with total bilirubin value $\leq 12 \mathrm{mg} / 100 \mathrm{~mL}$ in term babies and under $15 \mathrm{mg} / 100 \mathrm{~mL}$ in preterm babies. ${ }^{36}$

Pathological Jaundice: Total bilirubin level together with IMNCI clinical features was used to diagnose pathological jaundice. The neonates having one or more of the established IMNCI criteria (palms or/and soles yellow or skin and yellow eyes within $24 \mathrm{hrs}$ old or skin and eyes yellow, baby are $\geq 14$ days old) and total bilirubin more than $12 \mathrm{mg} / 100 \mathrm{~mL}$ at term and more than $15 \mathrm{mg} / 100 \mathrm{~mL}$ in the preterm baby was defined as pathologic jaundice. ${ }^{35,36}$
Kernicterus: Defined based on unconjugated hyperbilirubinemia of more than $340 \mathrm{Lmol} / \mathrm{L}$ in the term newborn or $200 \mathrm{Lmol} / \mathrm{L}$ in a preterm with features, such as poor sucking, vomiting, drowsiness, hypertonia, paralysis of upward gaze, high pitched cry, involuntary movements, and convulsions in the established category. ${ }^{37}$

Neonatal Sepsis: Defined based on the hematological criteria together with the IMNCI clinical features. The diagnostic criteria are based on one or more of the established IMNCI clinical features along with two or more hematological parameter abnormalities, such as total leukocyte count (4000 or $>12,000$ cells/m3), absolute neutrophil count $(1500$ cells $/ \mathrm{mm} 3$ or $>7500$ cells $/ \mathrm{mm} 3)$, erythrocyte sedimentation rate (ESR) $(>15 \mathrm{~mm} / 1 \mathrm{~h})$, and platelet count $(150$ or $>440$ cells $/ \mathrm{m} 3){ }^{38}$

$\mathrm{Rh}$ incompatibility: Defined as neonates with a different $\mathrm{Rh}$ blood group with their mother's as confirmed by laboratory testing. ${ }^{39}$

Event: Neonates who had developed jaundice up to discharge secondary to recovery or/and transferred to the pediatric ward.

Censored: Neonates who had not developed jaundice up to discharge due to recovery or/and transferred to the pediatric ward.

\section{Data Collection, Procedure, and Quality Assurance}

The data collection tool was adapted from the study conducted previously to ensure data quality. ${ }^{39}$ In addition, we verified the consistent understanding of the prepared collection tool by study participants through selecting and interviewing 34 samples randomly, which resulted in slight amendments to the data collection tool. Two first-degree graduate nurses who have been working in the NICU of Debre Markos comprehensive, specialized Hospital participated in data collection after they took 2 days of training on how to interview mothers, follow neonates and fill data in the questionnaire. The data were collected through interviews, observation, and extracting from medical records like bilirubin level, birth weight, and 5-min Apgar score. The investigator supervised the data collectors throughout the entire data collection process.

\section{Follow-Up Method}

The sample population was recruited at different times among admitted neonates in the neonatal intensive care unit of Debre Markos comprehensive specialized hospital. The trained data collectors recruited every fourth neonate 
among admitted neonates daily during the recruitment period. The data collectors registered the time and date of admission for those recruited neonates after they obtained written consent from mothers/guardians. These neonates were closely followed from their time of admission until they develop jaundice, discharge secondary to recovery, discharge to the pediatric ward after 28 days, and the end of the study period (June 30/2020). Those study participants who were developing jaundice during their follow-up period were considered as developing jaundice (event) but those neonates who were transferred to the pediatric ward after 28 days, discharging secondary to recovery without developing jaundice, and still admitted to NICU at the end of the study period were considered as censored. The time to develop jaundice among admitted neonates was calculated by subtracting time and date of admission from the time and date of discharge.

\section{A Method of Diagnosing Neonatal Jaundice}

In this study, during neonatal follow-up at NICU, a physician's diagnosis through clinical examination and laboratory investigation was used to classify neonatal jaundice. The bilirubin level was measured using blood sample taken from heel prick screening when there was clinical judgement by neonatologist or physician. During data collection, when physicians did not record the type of neonatal jaundice, those trained data collectors classified the type of jaundice using bilirubin level and IMNCI clinical features.

\section{Data Management}

\section{Data Processing and Analysis}

Data were entered into Epidata ${ }^{\mathrm{TM}}$ version 4.2 and analyzed using STATA ${ }^{\text {TM }}$ version 14.0 statistical software. At the end of the data collection period, the outcome of each study subject was dichotomized into censoring or event (Jaundice). In univariate analysis, we used to mean with standard deviations to describe normally distributed continuous data and median with interquartile range for skewed continuous data. The categorical data of the neonates were described using frequencies or percentages. Moreover, to identify the predictor variables, a cox-proportional hazard regression model was fitted. The KaplanMeier survival plot was used to estimate the survival time of their NICU admission to discharge and/or developing jaundice. A Generalized Log rank test was used to compare the survival curves between the categorical variables. The necessary assumption of the Cox-proportional hazard model was assessed using the Schoenfeld residual test and log-log plot and all variables fulfilled the assumption (the graphs did not cross or overlap each other). Regarding bivariable analysis, the outcome variable (Jaundice) and explanatory variables were entered into the Cox-proportional hazard regression model to select important variables for the multivariable Cox-proportional hazard regression model. As a result, variables having a "p-value" $\leq$ of 0.25 in the bi-variable analysis were fitted into the multivariable cox-proportion regression model. ${ }^{40}$ In the multivariable Cox-proportional hazard regression model, variables with "p-values" $<0.05$ were considered as statistically significant predictors. Adjusted relative risk with their $95 \%$ confidence intervals and p-values was used to measure the strength of association and identify statistically significant predictors of neonatal jaundice.

\section{Results}

\section{Sociodemographic Characteristics of the Mother}

In this study, 334 neonates with their mothers were included making a $98.8 \%$ response rate. The median $( \pm \mathrm{IQR})$ age of mothers was $27 \pm 7$ years, ranging from 16 to 42 years, and the age range of more than three-fourths of the mothers was between 20 and 35 years. About 253 (75.7\%) mothers were living in urban areas. Of the total interviewed mothers, 90 (26.9\%) were merchants by occupation. Regarding educational status, about 123 (36.8\%) of the study participants' mothers had college and above in their educational status. Their marital status revealed that 300 (89.8\%) mothers were married while 20 (4.9\%) were single mothers (Table 1 ).

\section{Characteristics of the Neonates}

Two hundred (59.8\%) neonates were male in their gender and about $267(80 \%)$ neonates were delivered at term with a birth weight of $2.5 \mathrm{~kg}$ and above. In this study, the APGAR score of 7-10 was recorded by 239 (71.5\%) neonates. In this study, the blood group of neonates was determined and the result indicated that about one-third of the neonates (32.8\%) were blood group "A", followed by "B" (28.4\%), "O" (21.8\%); and "AB" (17.0\%) were the least. About more than half $188(56.3 \%)$ of the neonates were $\mathrm{Rh}$ positive and exactly $136(40.8 \%)$ of the neonates had a family history of jaundice (Table 2). 
Table I Sociodemographic Characteristics of Mothers

\begin{tabular}{|l|l|l|l|}
\hline Variables & Category & Frequency & Percentage \\
\hline Mothers age & $18-20$ & 48 & 14.1 \\
& $20-35$ & 259 & 77.7 \\
& $>35$ & 28 & 8.2 \\
\hline Marital status & Single & 20 & 4.9 \\
& Married & 300 & 89.8 \\
& Divorced & 18 & 5.3 \\
\hline \multirow{2}{*}{ Residence } & Urban & 253 & 75.7 \\
& Rural & 81 & 24.3 \\
\hline \multirow{2}{*}{ Occupation } & House wives & 80 & 23.9 \\
& Farmer & 69 & 20.7 \\
& Governmental employee & 80 & 23.9 \\
& Merchant & 90 & 26.9 \\
& Student & 15 & 4.5 \\
\hline \multirow{2}{*}{ Educational status } & Not educated & 24 & 7.3 \\
& Primary & 65 & 19.5 \\
& Secondary & 49 & 14.6 \\
& Tertiary & 73 & 21.8 \\
& College and above & 123 & 36.8 \\
\hline
\end{tabular}

\section{Obstetric Characteristics}

The median (+IQ range) of parity was $1 \pm 2$ ranging from 1 to 5 live births. Three hundred twenty-three (96.9\%) respondents had antenatal care (ANC) follow up at least once during pregnancy, but $11(3.2 \%)$ had not. In this study, about $16(4.9 \%)$ of the mothers of the neonates

Table 2 Characteristics of the Neonates

\begin{tabular}{|l|l|l|l|}
\hline Variables & Category & Frequency & Percentage \\
\hline Gender & Male & 200 & 59.8 \\
& Female & 134 & 40.2 \\
\hline Blood group & A & 109 & 32.8 \\
& B & 95 & 28.4 \\
& AB & 57 & 17.0 \\
& O & 73 & 21.8 \\
\hline Rh type & Negative & 146 & 43.7 \\
& Positive & 188 & 56.3 \\
\hline $\begin{array}{l}\text { Gestational age at birth } \\
\text { (in weeks) }\end{array}$ & $37-42$ & 267 & 80 \\
\hline Birth weight (kg) & $<37$ & 67 & 20 \\
\hline Five minute APGAR & $\leq 2.5$ & 67 & 20 \\
score & $\geq 2.5$ & 267 & 80 \\
\hline Family history of & $7-10$ & 239 & 71.5 \\
\hline jaundice & Yes & 136 & 40.8 \\
\hline
\end{tabular}

had experienced gestational diabetes mellitus during their pregnancy, and $41(12.1 \%)$ of mothers were developing gestational hypertension. Among neonatal mothers, exactly $24(7.3 \%)$ of them were experiencing the premature rupture of membrane (PROM) and 33 (9.7\%) of them had hyperemesis gravidarum which were identified as an obstetric complication. With regard to the mode of delivery, spontaneous vaginal delivery accounted for 240 $(71.9 \%)$ whereas instrumental and cesarean section 50 (14.9\%) and 44 (13.2\%) mothers, respectively. The duration of labor ranges from 4 to 72 hours, of which the normal duration of labor was represented by 234 (69.9\%) participants. For induction of labor, 156 (46.6\%) mothers have used oxytocin (Table 3).

\section{Medical Factors}

About three-fourths 253 (75.7\%) mothers took drugs during pregnancy and iron with folic acid 307 (91.8\%), magnesium sulfate $51(15.1 \%)$ and others $17(5.1 \%)$ of them took other drugs. Regarding substance use, 289 (86.4\%) of mothers have used alcohol, 15 (4.5\%) of mothers were used chat, and $77(23 \%)$ of mothers were used herbs medicinally during their pregnancy. The blood group of mothers was determined; as a result, blood groups "A" "B", "AB", and "O" were found to be $31.8 \%, 29.4 \%, 15.0 \%$, and $23.8 \%$,

Table 3 Obstetric Characteristics

\begin{tabular}{|c|c|c|c|}
\hline Variables & Category & Frequency & Percentage \\
\hline Parity & $\begin{array}{l}0 \text { previous live } \\
\text { born } \\
\geq \text { I previous live } \\
\text { born }\end{array}$ & $\begin{array}{l}80 \\
332\end{array}$ & $\begin{array}{l}19.4 \\
80.6\end{array}$ \\
\hline ANC follow-up & $\begin{array}{l}\text { No } \\
\text { Yes }\end{array}$ & $\begin{array}{l}11 \\
323\end{array}$ & $\begin{array}{l}3.2 \\
96.9\end{array}$ \\
\hline $\begin{array}{l}\text { Premature rapture of } \\
\text { membrane(PROM) }\end{array}$ & $\begin{array}{l}\text { No } \\
\text { Yes }\end{array}$ & $\begin{array}{l}310 \\
24\end{array}$ & $\begin{array}{l}92.7 \\
7.3\end{array}$ \\
\hline $\begin{array}{l}\text { Gestational diabetes } \\
\text { mellitus }\end{array}$ & $\begin{array}{l}\text { No } \\
\text { Yes }\end{array}$ & $\begin{array}{l}318 \\
16\end{array}$ & $\begin{array}{l}95.2 \\
4.9\end{array}$ \\
\hline Gestational hypertension & $\begin{array}{l}\text { No } \\
\text { Yes }\end{array}$ & $\begin{array}{l}293 \\
41\end{array}$ & $\begin{array}{l}87.9 \\
12.1\end{array}$ \\
\hline Hyperemesis gravidarum & $\begin{array}{l}\text { No } \\
\text { Yes }\end{array}$ & $\begin{array}{l}301 \\
33\end{array}$ & $\begin{array}{l}90.3 \\
9.7\end{array}$ \\
\hline Mode of delivery & $\begin{array}{l}\text { Spontaneous } \\
\text { Instrumental } \\
\text { Caesarean section }\end{array}$ & $\begin{array}{l}240 \\
50 \\
44\end{array}$ & $\begin{array}{l}71.9 \\
14.9 \\
13.3\end{array}$ \\
\hline $\begin{array}{l}\text { Use of oxytocin for } \\
\text { induction }\end{array}$ & $\begin{array}{l}\text { No } \\
\text { Yes }\end{array}$ & $\begin{array}{l}178 \\
156\end{array}$ & $\begin{array}{l}53.4 \\
46.6\end{array}$ \\
\hline
\end{tabular}


respectively. Among the study participants, 100 (30\%) of them had sepsis medical complications. Of the neonates, 84 (25\%) had ABO blood group incompatibility and 75 (22\%) $\mathrm{Rh}$ blood type incompatibility and were documented as they had medical complications.

\section{Rate of Neonatal Jaundice}

In this study, neonates had had a follow-up time ranging from 3 hours to 28 days during their admission period. In the follow-up, about 90 neonates were developing jaundice (20 pathologic and 70 physiologic jaundice). The study participants had 2000 person-hours of jaundice free time. The overall rate of neonatal jaundice was 4.5 per 100 person-hours. All jaundiced neonates took phototherapy as a mode of treatment, but no blood transfusion exchange. The overall incidence rate (Figure 1), and for important variables like the incidence rate of neonatal jaundice over their Sepsis status (Figure 2), survival status of neonates over their sex (Figure 3) and the survival

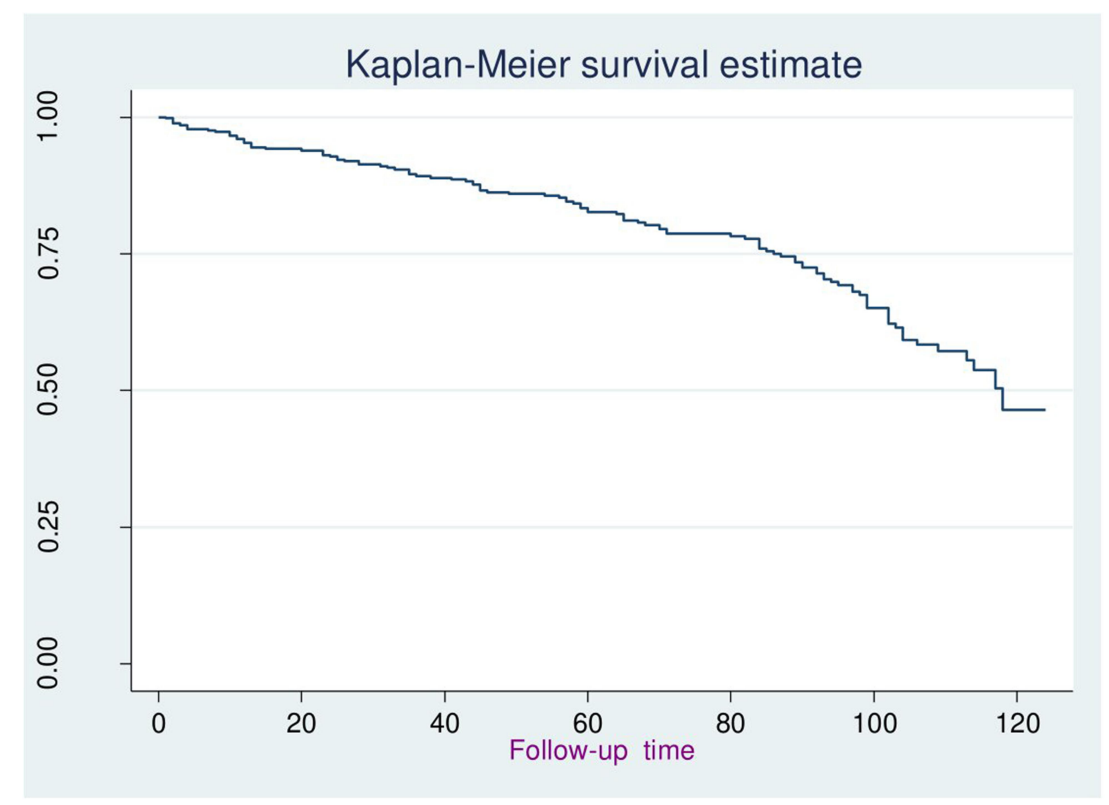

Figure I The overall survival status of the neonates.

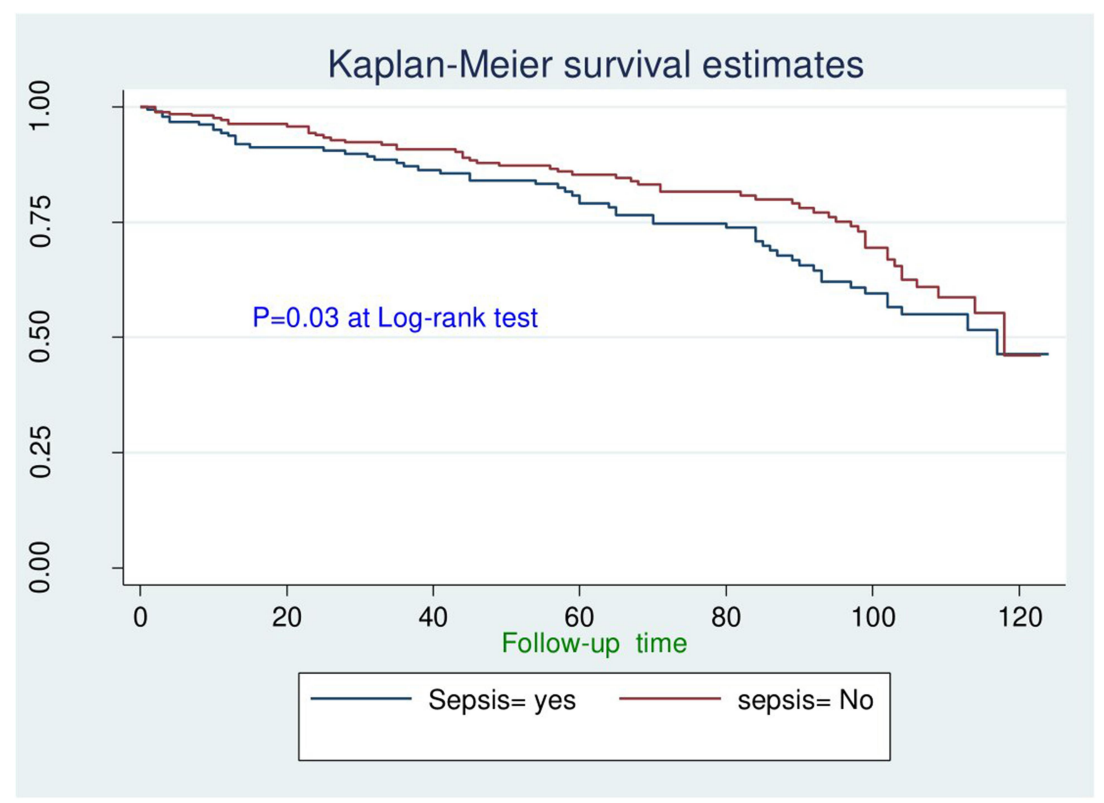

Figure 2 Survival status of neonates free from jaundice. 
probability of the neonates over their ABO blood group incompatibility status (Figure 4) were presented.

\section{Bivariate and Multivariable Cox- Regression Analysis}

During bivariate cox-proportional regression analysis, Apgar score, duration of labor, sex of neonates, maternal blood group, neonatal blood group, sepsis, type incompatibility, mode of delivery, Premature rupture of the membrane, and ANC follow-up were found as a candidate for multivariable cox-regression analysis model since they had a "p-value" less than 0.25 to include clinically important variables.

Multivariable Cox-proportional regression analysis was done by taking variables having a significant association on bivariable cox-proportional hazard regression analysis at a "p-value" of $\leq 0.25$ to include important variables. In multivariable logistic regression analysis

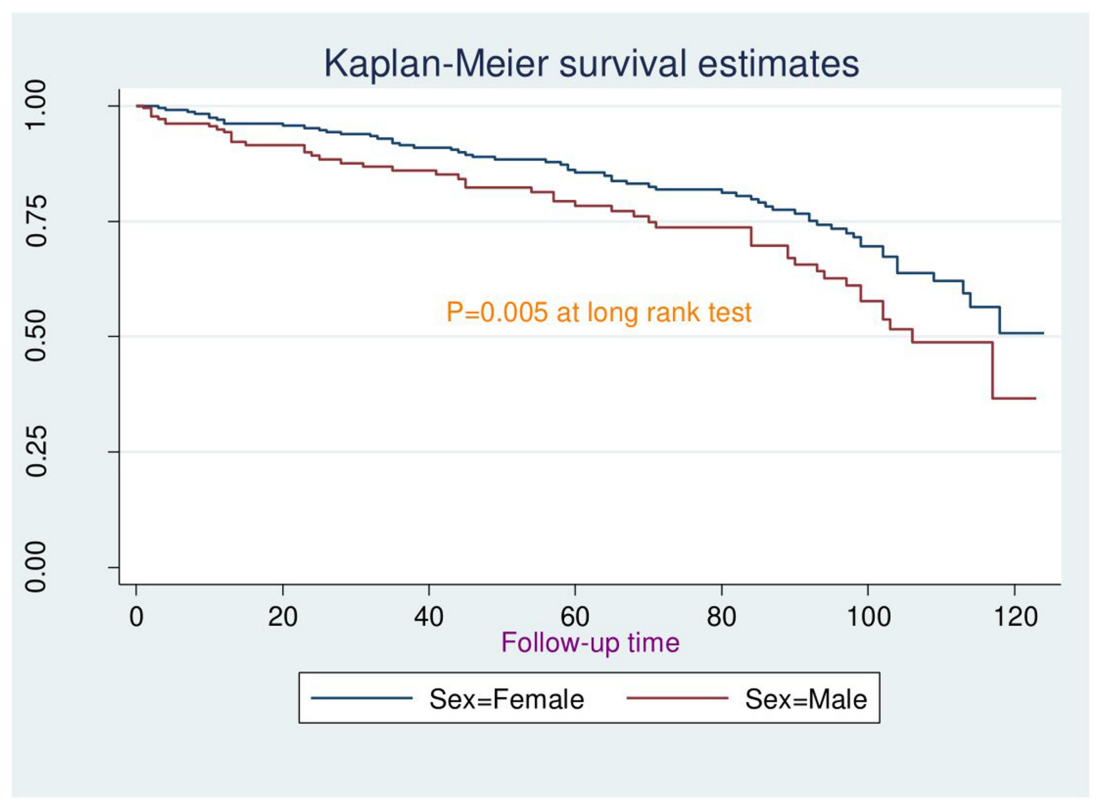

Figure 3 Survival probability of neonates over their sex.

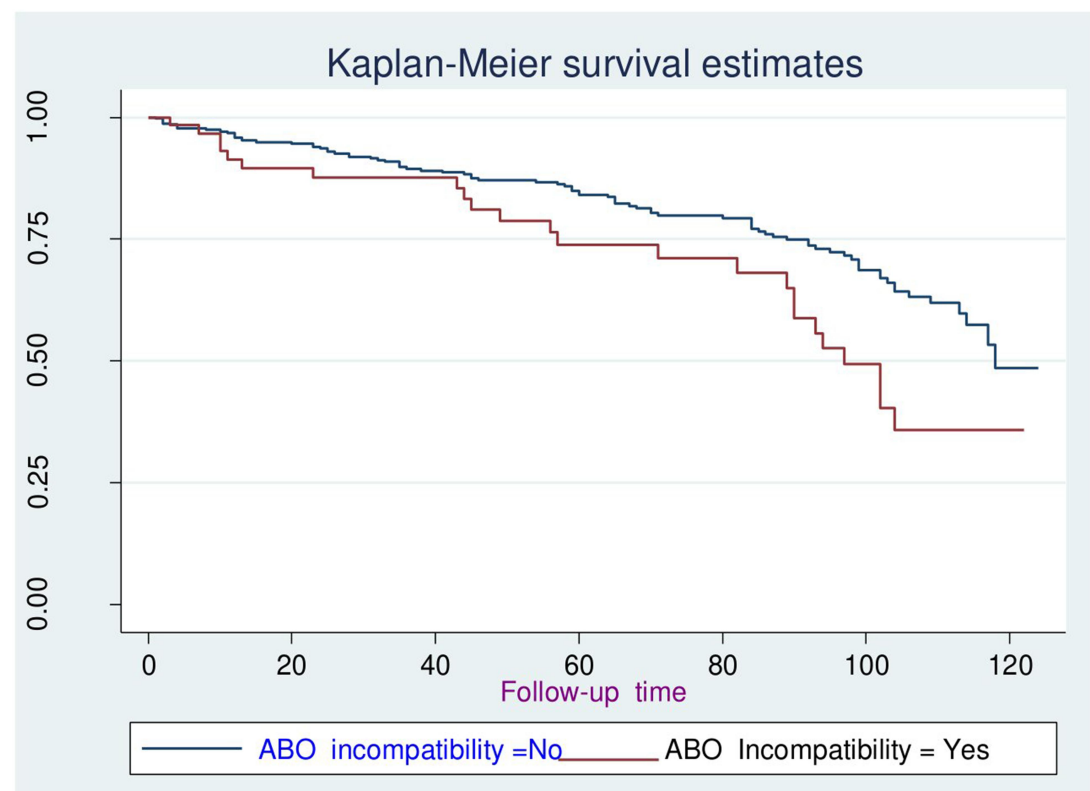

Figure 4 Survival probability of the neonates over their ABO blood group incompatibility status. 
prolonged duration of labor, mothers' O blood group, being male neonates, and blood incompatibility had a significant association with neonatal jaundice at "pvalue" $<0.05$.

The finding of this study showed that the hazard rate of having neonatal jaundice among neonates who were delivered with a long duration of labor was $3.5[\mathrm{ARR}=3.5 ; 95 \%$ CI (2.8-8.7)] times higher as compared with those who were delivered with a normal duration of labor. The relative risk of neonatal jaundice among male neonates was 5.2 $[\mathrm{ARR}=5.2 ; 95 \% \mathrm{CI}(3.5-7.3)]$ times higher when compared with those female neonates. In the same way, the risk rate of developing neonatal jaundice among neonates whose mother had "O" blood group was five $[\mathrm{ARR}=4.5 ; 95 \%$ CI (3.4-10.3)] times higher as compared with those neonates whose mother had " $A$ " blood group. The relative risk of neonatal jaundice among neonates who had sepsis was $3.4[\mathrm{ARR}=3.4 ; 95 \% \mathrm{CI}(2.5-6.1)]$ times higher compared with those neonates who had no sepsis diagnosis (Table 4).

Table 4 Multivariable Cox Proportional Hazard Regression Analysis

\begin{tabular}{|c|c|c|c|c|c|}
\hline \multirow[t]{2}{*}{ Variables } & \multirow[t]{2}{*}{ Category } & \multicolumn{2}{|c|}{ Event } & \multirow{2}{*}{$\begin{array}{l}\text { Adjusted } \\
\text { Relative Risk } \\
\text { (ARR) }(95 \% \\
\text { Cl) }\end{array}$} & \multirow[t]{2}{*}{ P-value } \\
\hline & & Yes & No & & \\
\hline \multirow[t]{2}{*}{ Duration of labour } & Normal & 30 & 200 & 1.0 & \\
\hline & Prolonged & 60 & 44 & $3.5(2.8-8.7)$ & $0.010 *$ \\
\hline \multirow[t]{2}{*}{ Sex of neonate } & Female & 33 & 101 & 1.0 & \\
\hline & Male & 57 & 143 & $5.2(3.5-7.3)$ & $0.003 *$ \\
\hline Five minute & $\leq 6$ & 65 & 30 & I.I (0.4-2.8) & 0.775 \\
\hline APGAR score & $7-10$ & 25 & 214 & 1.0 & \\
\hline \multirow{4}{*}{$\begin{array}{l}\text { Neonates blood } \\
\text { group }\end{array}$} & A & 30 & 79 & & \\
\hline & B & 25 & 70 & $0.9(0.2-3.7)$ & 0.697 \\
\hline & $A B$ & 15 & 42 & $0.5(0.1-2.8)$ & 0.967 \\
\hline & O & 20 & 53 & I.7(0.6-5.2) & 0.531 \\
\hline \multirow{4}{*}{$\begin{array}{l}\text { Mothers blood } \\
\text { group }\end{array}$} & A & 32 & 74 & 1.0 & \\
\hline & B & 23 & 75 & $2.7(0.8-8.6)$ & 0.70 \\
\hline & $A B$ & 17 & 33 & $0.6(0.6-22.3)$ & 0.751 \\
\hline & O & 18 & 62 & $4.5(3.4-10.3)$ & $0.012^{*}$ \\
\hline \multirow[t]{2}{*}{ Sepsis } & Yes & 54 & 46 & $2.6(1.2-6.1)$ & $0.022 *$ \\
\hline & No & 36 & 198 & 1.0 & \\
\hline \multirow{2}{*}{$\begin{array}{l}\text { Blood type } \\
\text { incompatibility }\end{array}$} & Yes & 64 & 20 & $3.2(6.4-52.1)$ & 0.20 \\
\hline & No & 26 & 224 & 1.0 & \\
\hline
\end{tabular}

Note: *To show predictor variables having significant association with the outcome variable.

Abbreviations: ARR, adjusted relative risk; $\mathrm{Cl}$, confidence interval.

\section{Discussions}

Neonatal jaundice has significant importance or contribution to neonatal morbidity and mortality worldwide. The vast majority of the affected neonates due to jaundice reside in sub-Saharan Africa and South Asia. ${ }^{37,41}$ There are insufficient recorded data on the rate and predictors of neonatal jaundice in Ethiopia. Hence, this study aimed at determining the rate and predictors of neonatal jaundice among neonates admitted at the neonatal intensive care unit of Debre Markos comprehensive specialized hospital, Northern Ethiopia.

In this study, the incidence rate of neonatal jaundice was 4.5 (ARR: 4.5, 95\% CI: 2.1 -6.7) per 100 personhours, which is supported by the study conducted previously. ${ }^{42}$ This incidence rate of neonatal jaundice at Debre Markos town was high as compared to the previous studies. This might be due to $30 \%$ of the neonates were had sepsis and $25 \%$ of them had blood type incompatibility. This research showed that neonatal sepsis was a significant predictor for neonatal jaundice.

This study had shown that the relative risk of jaundice was about $3.5[\mathrm{ARR}=3.5 ; 95 \% \mathrm{CI}(2.8-8.7)]$ times higher among neonates who were born with a long duration of labor compared with those neonates born in normal time of labor. This finding was in line with the finding in Nepal. ${ }^{11}$ This might be attributed to the bruising and swelling of the scalp of newborns due to the excessive pressure applied by birth attendants as a solution for prolonged labor, which increases the risk of jaundice by increasing bilirubin levels in the blood. ${ }^{39}$

This study revealed that being male neonates had 5.2 $[\mathrm{ARR}=5.2 ; 95 \% \mathrm{CI}(3.5-7.3)]$ times higher risk of developing neonatal jaundice as compared to their female counterparts. This finding was supported by studies done in Nepal ${ }^{11}$ and Nigeria. ${ }^{43}$ This finding could explain that male newborns have relatively immature liver, which may not be able to process all the bilirubin formed from red blood cells. ${ }^{39}$ It was also found that the rate of developing neonatal jaundice among neonates whose mother had "O" blood group was almost five $[\mathrm{ARR}=4.5$; 95\% CI (3.4-10.3)] times higher compared with those neonates whose mother had "A" blood group. However, a study done in Iran showed that mothers of the "O" blood group had no significant effect on the development of neonatal jaundice. ${ }^{44}$ It might be due to the mother's blood containing anti-A, B antibodies that are usually $\operatorname{IgG}$ antibodies that cross the placental barrier and attack the fetus or newborn red cells containing $\mathrm{A}, \mathrm{B}$, or $\mathrm{AB}$ antigens and cause jaundice. 
Furthermore, this study revealed that neonatal jaundice had a significant association with sepsis. The relative rate of developing neonatal jaundice among neonates who had sepsis was about 3.4 (AHR: 3.4, 95\% CI (2.5-6.1)) times higher compared with those neonates who had no sepsis diagnosis. It was supported and identified as the possible causes of neonatal jaundice in studies conducted in India, ${ }^{41,45,46}$ Iran, ${ }^{47,48}$ and Nigeria. ${ }^{37,49}$ This might be because sepsis might be the cause of hemolysis of red blood. As well as in those neonates diagnosed with neonatal sepsis, there is an elevation of bilirubin level in serum due to an inability on the part of the cell to excrete conjugated bilirubin secondary to intracellular accumulation of unconjugated bilirubin and by "toxic" cellular alterations. ${ }^{50}$

\section{Limitation of This Study}

As a limitation, this study was not considered some essential predictors, like a thyroid-stimulating hormone, and glucose-6-phosphatase dehydrogenase.

\section{Conclusion}

Neonatal jaundice among neonates admitted in Debre Markos comprehensive, specialized hospital was high. Prolonged duration of labor, maternal "O" blood group, blood type incompatibility, and sepsis were the independent predictors of neonatal jaundice. Hence, an effort has to be made to decrease the incidence rate of neonatal jaundice through improving newborn care and timely intervention for neonates with sepsis and delivered at long duration of time as well as the neonates born from "o" blood type mothers are our recommendation.

\section{Abbreviations}

NICU, Neonatal Intensive care unit; MRN, Medical Registration Number; AHR, Adjusted Hazard Rate; PROM, Premature Rapture of Membrane; CI, Confidence Interval; APGAR, Appearance Pulse Grimace response Activity Respiration; ANC, Antenatal care; IMNCI, Integrated Management of Childhood Illness.

\section{Data Sharing Statement}

Data will be accessed upon request of the corresponding author.

\section{Ethics Approval and Consent to Participate}

We obtained the ethical clearance approval letter from the Ethical review committee of Debre Markos University
College of Health Sciences. During the data collection period, the administrative bodies of Debre Markos comprehensive specialized hospital were also allowed to conduct the research and written informed consent was taken from parents or/and guardians of the neonates. All parents or guardians who were participated in this study were greater than 18 years old. To keep the confidentiality, the information of the study participants was not disclosed to anyone other than the principal investigators. Generally, this study was conducted in accordance with the World Medical Association Declaration of Helsinki.

\section{Acknowledgments}

The authors extended their special thanks to both data collectors and supervisors.

\section{Author Contributions}

All the authors made a significant contribution to the work reported (study design, execution, acquisition of data, analysis and interpretation); have agreed on the journal to which the article has been submitted; and agree to be accountable for all aspects of the work.

\section{Funding}

There is no funding to report.

\section{Disclosure}

The authors have declared that they have no conflicts of interest for this work.

\section{References}

1. Effiong G, Laditan A. Neonatal jaundice in lliaalan: a Study of Cases seen in the Out-Patient Clinic. 1976.

2. Richard A, Pamela C. Lippincott's Illustrated Review of Biochemistry. New York: Lippincott Williams \& Wilkin's; 2011.

3. Karayalcin G. Sickle cell anemia in the neonatal period. South Med J. 1979;72(4):492-493. doi:10.1097/00007611-197904000-00034

4. Mitra S, Rennie J. Neonatal jaundice: aetiology, diagnosis and treatment. $B r \quad J$ Hosp Med. 2017;78(12):699-704. doi:10.12968/ hmed.2017.78.12.699

5. Ullah S, Rahman K, Hedayati M. Hyperbilirubinemia in neonates: types, causes, clinical examinations, preventive measures and treatments: a narrative review article. Iran J Public Health. 2016;45 (5):558.

6. Chou S-C, Palmer RH, Ezhuthachan S, et al. Management of hyperbilirubinemia in newborns: measuring performance by using a benchmarking model. Pediatrics. 2003;112(6):1264-1273. doi:10.1542/ peds.112.6.1264

7. Moerschel SK, Cianciaruso LB, Tracy LR. A practical approach to neonatal jaundice.. Am Fam Physician. 2008;77(9):1255-1262.

8. Lawn JE, Cousens S, Zupan J, Team LNSS. 4 million neonatal deaths: when? Where? Why? Lancet. 2005;365(9462):891-900. doi:10.1016/ S0140-6736(05)71048-5 
9. Bhutani VK, Zipursky A, Blencowe H, et al. Neonatal hyperbilirubinemia and Rhesus disease of the newborn: incidence and impairment estimates for 2010 at regional and global levels. Pediatr Res. 2013;74(S1):86-100. doi:10.1038/pr.2013.208

10. Abdo RA, Halil HM, Kebede BA, Anshebo AA, Gejo NG. Prevalence and contributing factors of birth asphyxia among the neonates delivered at Nigist Eleni Mohammed memorial teaching hospital, Southern Ethiopia: a cross-sectional study. BMC Pregnancy Childbirth. 2019;19 (1):536. doi:10.1186/s12884-019-2696-6

11. Scrafford CG, Mullany LC, Katz J, et al. Incidence of and risk factors for neonatal jaundice among newborns in southern Nepal. Tropical Med Int Health. 2013;18(11):1317-1328. doi:10.1111/tmi.12189

12. Sarici SU. Incidence and etiology of neonatal hyperbilirubinemia. $J$ Trop Pediatr. 2010;56(2):128-129. doi:10.1093/tropej/fmp041

13. Gurley ES, Halder AK, Streatfield PK, et al. Estimating the burden of maternal and neonatal deaths associated with jaundice in Bangladesh: possible role of hepatitis E infection. Am J Public Health. 2012;102 (12):2248-2254. doi:10.2105/AJPH.2012.300749

14. Tette EM, Nartey ET, Nuertey BD, et al. The pattern of neonatal admissions and mortality at a regional and district hospital in the Upper West Region of Ghana; a cross sectional study. PLoS One. 2020;15(5):e0232406. doi:10.1371/journal.pone.0232406

15. Hadgu FB, Gebretsadik LG, Mihretu HG, Berhe AH. Prevalence and Factors Associated with Neonatal Mortality at Ayder Comprehensive Specialized Hospital, Northern Ethiopia. A Cross-Sectional Study. Pediatric Health Med Therapeutics. 2020;11:29. doi:10.2147/ PHMT.S235591

16. Limaso AA, Dangisso MH, Hibstu DT. Neonatal survival and determinants of mortality in Aroresa district, Southern Ethiopia: a prospective cohort study. BMC Pediatr. 2020;20(1):33. doi:10.1186/ s12887-019-1907-7

17. Yismaw AE, Tarekegn AA. Proportion and factors of death among preterm neonates admitted in University of Gondar comprehensive specialized hospital neonatal intensive care unit, Northwest Ethiopia. BMC Res Notes. 2018;11(1):867. doi:10.1186/s13104-018-3970-9

18. Trg AC, Wegrzyn GH, et al. Umbilical cord blood bilirubins, gestational age, and maternal race predict neonatal hyperbilirubinemia. PloS one. 2017;13:0197888.

19. Carolyn G. Incidence of and risk factors for neonatal jaundice among newborns in southern Nepal. Tropical Med Int Health. 2002;18:131.

20. Ehsan Garosi FM, Ranjkesh F. The Relationship between Neonatal Jaundice and Maternal and Neonatal Factors. Iranian J Neonatology IJN. 2014;7:37.

21. Dakoru Edoghotu Omekwe MDG, Briseimo T. Survey and management outcome of neonatal jaundice from a developing tertiary health centre, Southern Nigeria. IOSR J Dental Med Sci. 2012;13:35.

22. Rkde PA, Kontor KA, et al. Knowledge level and determinants of neonatal jaundice: a cross-sectional study in the effutu municipality of ghana. Int $J$ Pediatrics. 2016.

23. Sudha Menon NA. Maternal and neonatal determinants of neonatal jaundice - a case control study. J Med Sci Cli Res. 2017;5:19656.

24. Mikael Norman M. The prevalence of neonatal jaundice and risk factors in healthy term neonates at National District Hospital in Bloemfontein. Predicting Nonhemolytic Neonatal Hyperbilirubinemia. 2015;136:6.

25. Zohreh Kavehmanesh M, Gastroentrologist P, Mohammadieh NE, et al. Prevalence of Readmission for Hyperbilirubinemia in Healthy Newborns. 2004.

26. Reza Tavakolizadeh AI, Seirafi G, Khedmat L, et al. Maternal risk factors for neonatal jaundice: a hospital-based cross-sectional study in Tehran. Eur J Translat Myology. 2010;28.

27. Sayed Yousef Mojtahedi AI, Seirafi G, Khedmat L, Tavakolizadeh R. Risk factors associated with neonatal jaundice. J Med. 2018;8:1387.

28. Bolajoko O, Olusanya FBO, Tina M. Slusher. Risk factors for severe neonatal hyperbilirubinemia in low and middle-income countries: a systematic review and meta-analysis. 2014.
29. Hanneke Brits JA, Huisamen Y, Beukes D, et al. The prevalence of neonatal jaundice and risk factors in healthy term neonates at National District Hospital in Bloemfontein. African Primary Health Care. 2016;10:1-6.

30. Ael MA, Zahraa Mohamed E. Role of bilirubin and albumin in cord blood as predictors for neonatal hyperbilirubinemia. $J$ Gynecol Res. 2017;4:208.

31. Tinuade A. Predictors of acute bilirubin encephalopathy among Nigerian term babies with moderate-to-severe hyperbilirubinaemia. J Tropical pediatrics. 2009;57:80.

32. Chukwu. A.U FSA. Determinant of neonatal jaundice: a logistic regression and correspondence analysis approach. Int J Modern Math Sci. 2015;37:275.

33. Eyasu A, Lake GBA, Gedion A. Magnitude of neonatal jaundice and its associated factor in neonatal intensive care units of Mekelle city public hospitals, Northern Ethiopia. Int J Pediatrics. 2016.

34. FMOH. National Strategy for Newborn and Child Survival in Ethiopia; 2017.

35. Azzuqa A, Watchko JF. Bilirubin concentrations in jaundiced neonates with conjunctival icterus. J Pediatr. 2015;167(4):840-844. doi:10.1016/j.jpeds.2015.06.065

36. Health eFMo. Integrated Management of Childhood Illness (IMNCI), "Classify all sick young infants for jaundice Addis Ababa," Ethiopia; 2011. Available from: http://www.open.edu/openlearncreate/plugin fle.php/71991/modresource/content/2/IMNCIPart2FinalPrintreadyMarch2011.pdf. Accessed 9 February 2020.

37. Onyearugha C, Onyire B, Ugboma H. Neonatal jaundice: prevalence and associated factors as seen in Federal medical centre Abakaliki, Southeast Nigeria. J Clin Med Res. 2011;3(3):40-45.

38. Gebremedhin D, Berhe H, Gebrekirstos K. Risk factors for neonatal sepsis in public hospitals of Mekelle City, North Ethiopia, 2015: unmatched case control study. PLoS One. 2016;11(5):e0154798. doi:10.1371/journal.pone. 0154798

39. Lake EA, Abera GB, Azeze GA, Gebeyew NA, Demissie BW. Magnitude of neonatal jaundice and its associated factor in neonatal intensive care units of Mekelle city public hospitals, Northern Ethiopia. Int J Pediatr. 2019;1-9. doi:10.1155/2019/1054943

40. Jr DW H, Lemeshow S, Sturdivant RX. Applied Logistic Regression. Vol. 398. John Wiley \& Sons; 2013.

41. Gutta S, Shenoy J, Kamath SP, et al. Light emitting diode (LED) phototherapy versus conventional phototherapy in neonatal hyperbilirubinemia: a single blinded randomized control trial from coastal India. Biomed Res Int. 2019;2019:1-6. doi:10.1155/2019/6274719

42. Jones KD, Grossman SE, Kumaranayakam D, Rao A, Fegan G, Aladangady N. Umbilical cord bilirubin as a predictor of neonatal jaundice: a retrospective cohort study. BMC Pediatr. 2017;17(1):186. doi:10.1186/s12887-017-0938-1

43. Olusanya B, Akande A, Emokpae A, Olowe S. Infants with severe neonatal jaundice in Lagos, Nigeria: incidence, correlates and hearing screening outcomes. Tropical Med Int Health. 2009;14(3):301-310. doi:10.1111/j.1365-3156.2009.02223.x

44. Kavehmanesh Z, Ebrahimi MN, Torkaman M. Prevalence of readmission for hyperbilirubinemia in healthy newborns. 2008.

45. Paridhi G, Nilesh D, Sumit A, Vinit W. Study of Etiology of Neonatal Jaundice at tertiary care centre in Maharashtra. SJAMS ISSN. 2015;2320-6691.

46. Ali A, Tomar A. Etiological profile of neonatal hyperbilirubinaemia in the rural area of Rajasthan. Indian J Basic App Med Res. 2015;4 (2):223-232.

47. Najib KS, Saki F, Hemmati F, Inaloo S. Incidence, risk factors and causes of severe neonatal hyperbilirubinemia in the South of Iran (fars province). Iran Red Crescent Med J. 2013;15(3):260. doi:10.5812/ircmj.3337

48. Boskabadi H, Ashrafzadeh F, Azarkish F, Khakshour A. Complications of Neonatal Jaundice and the Predisposing Factors in Newborns. J BABOL Univ Med Sci. 2015;17(9):7-13. 
49. Omekwe DE, George MD, Kennis BT, et al. Survey and management outcome of neonatal jaundice from a developing tertiary health centre, Southern Nigeria. IOSR J Dental Med Sci. 2014;13(4):35-39. doi: $10.9790 / 0853-13413539$
50. Dunham EC. Septicemia in the new-born. Am $J$ Dis Children. 1933;45(2):229-253.

\section{Publish your work in this journal}

The Journal of Multidisciplinary Healthcare is an international, peerreviewed open-access journal that aims to represent and publish research in healthcare areas delivered by practitioners of different disciplines. This includes studies and reviews conducted by multidisciplinary teams as well as research which evaluates the results or conduct of such teams or healthcare processes in general. The journal covers a very wide range of areas and welcomes submissions from practitioners at all levels, from all over the world. The manuscript management system is completely online and includes a very quick and fair peer-review system. Visit http://www.dovepress.com/testimonials. php to read real quotes from published authors. 